\title{
A ANÁLISE DE LIVRO DIGITAL: uma visão de suas affordances
}

\author{
Maurício Elias Dick \\ Universidade Federal de Santa Catarina (UFSC) \\ mauricioedick@gmail.com \\ Berenice Santos Gonçalves \\ Universidade Federal de Santa Catarina (UFSC) \\ berenice@cce.ufsc.br
}

Resumo: A tecnologia muda à medida que amadurece e juntamente a essa mudança, proporciona ao usuário diferentes tipos de interação, procurando aprimorar os aspectos dessa experiência, por meio de melhoramentos na ergonomia do dispositivo e na usabilidade das interfaces. Tornar a experiência do usuário mais agradável faz esse se sentir mais confortável frente à tecnologia. Além disso, onde há uma interface, impreterivelmente ocorrerá uma interação entre o homem e a máquina. Sendo assim, por serem interativos e se apresentarem no meio virtual, os livros digitais também são interfaces, fazendo-se imprescindível a aplicação dos princípios que envolvem o design de interação para que o projeto seja o mais bem adaptado àquele usuário e àquela tarefa. Desse modo, este estudo teve por objetivo avaliar as affordances presentes no uso de um protótipo de livro digital interativo e, para tal, o método empregado foi a utilização de uma lista de verificação de affordance. Concluiu-se então que affordances percebidas são necessárias para a concepção de livros digitais que sejam claros, coesos e de fácil utilização e que as falsas affordances podem ser geradas pela falta de coerência visual dos elementos que compõem a interface.

Palavras-chave: análise, interação, affordance, livro digital, tablet.

Abstract: Technology changes as it matures and along with that change, it provides the user different kinds of interactions, seeking to improve the aspects of this experience, through improvements on the device ergonomics and on the interface usability. Making the user experience more enjoyable makes this feels more comfortable facing the technology. Furthermore, where there is an interface, imperatively there will be an interaction between man and machine. Thus, for being interactive and presenting themselves in the virtual environment, the e-books are also interfaces, making indispensable the application of the interaction design principles so that the project is the most adapted to that user and that task. 
Thereby, this study aimed to evaluate the presented affordances during the use of an interactive e-book prototype and for this the method employed was the use of an affordance checklist. It has been concluded that perceived affordances are necessary to the conception of e-books that are clear, cohesive and easy to use and that false affordances can be generated by the lack of visual coherency of the elements that compound the interface.

Keywords: analysis, interaction, affordance, e-book, tablet.

\subsection{INTRODUÇÃO}

O presente artigo traz como escopo principal uma avaliação dos níveis de affordances presentes em um protótipo de livro digital para uso em tablets, desenvolvido por um dos autores.

Passados três anos desde sua conclusão, julga-se necessária uma análise de seu uso, visto que a tecnologia em questão já se torna mais inserida no contexto diário do público em foco.

Como afirma Norman (2011), a tecnologia muda à medida que amadurece. Juntamente a essa mudança, proporciona ao usuário diferentes tipos de interação tanto por meio de suas ferramentas, como pelo modo de entrada de dados/comandos - e procura melhorar os aspectos dessa experiência, por meio de melhoramentos na ergonomia do dispositivo e na usabilidade das interfaces. Tornar a experiência do usuário mais agradável faz esse se sentir mais confortável frente à tecnologia.

Além disso, onde há uma interface, impreterivelmente ocorrerá uma interação entre o homem e a máquina. Sendo assim, por serem interativos e se apresentarem no meio virtual, os livros digitais também são interfaces, fazendo-se imprescindível a aplicação dos princípios que envolvem o design de interação para que o projeto seja o mais bem adaptado àquele usuário e àquela tarefa.

Desse modo, este estudo tem por objetivo avaliar as affordances presentes no uso de um protótipo de livro digital interativo e, para tal, o método empregado é a utilização de uma lista de verificação de affordance, proposta por Legaspi e Jakhu (2014).

\section{LIVRO DIGITAL}

O mercado de livros digitais se encontra ainda em sua infância, sendo assim, por ser de um passado recente, o livro digital ainda não é definido por um só termo e-book, livro eletrônico, livro digital, entre outros - e, por consequência não possui um conceito único ou uniforme (SILVA, 2002).

Pinksy (2009) faz um resumo de definições de diferentes autores:

Segundo Lynch (2001) livro eletrônico é um conjunto de bits que pode ser transportado por mídia eletrônica ou entregue via rede e desenhado para ser visto em uma combinação de software e hardware, mas existem independentemente dos mecanismos que podem ser usados para acessá-los ou lê-los. Gibson e Ruotolo (2003) definem o livro eletrônico como qualquer texto completo e eletrônico feito para ser lido em uma tela desde que não em um 
navegador da internet. Para Anuradha e Usha (2006), é um texto eletrônico que serve aos mesmos propósitos que um livro impresso e pode parecer fisicamente com ele. De acordo com computador ou lido em algum aparelho portátil. Para Gunter (2005) é qualquer sequência de texto do tamanho de uma monografia, ou livro disponível em formato eletrônico (PINKSY, 2009, p. 29).

Já Procópio (2010) propõe uma divisão do livro digital em três dimensões. 0 assunto e-book envolve o reader (leitor), o qual é o aplicativo (software) que proporciona a leitura do livro na tela; o dispositivo (hardware) de leitura, portátil ou não, que é o recipiente ou suporte do livro; e o livro em si, ou seja, o conteúdo.

Santaella (2013) também propõe uma separação do livro digital, porém em duas dimensões: o conteúdo em si (referido como e-book) e o seu suporte de leitura (e-reader).

O e-reader é um dispositivo eletrônico portátil, cuja função é a leitura de livros e periódicos digitais. Em teoria, qualquer dispositivo eletrônico capaz de apresentar um texto em uma tela pode ser nomeado como um leitor de livros digitais, porém, existem leitores dedicados e leitores híbridos ${ }^{1}$.

Ao explorar a capacidade multimídia dos tablets, proporciona-se a aparição dos chamados livros aplicativo, os quais se utilizam de diversos recursos interativos e de informações em variados modos (imagem, som, vídeo, etc.), transformando os tradicionais hábitos de leitura. Por serem interativos e se apresentarem no meio virtual, os livros digitais também são, portanto, uma interface interativa, fazendo-se necessária a aplicação dos princípios que envolvem o design de interação durante todo o seu processo de projeto.

\subsection{INTERAÇÃO E INTERFACE}

Levy define "interface" como o termo utilizado "para todos os aparatos materiais que permitem a interação entre o universo da informação digital e o mundo ordinário" (LEVY, 1999, p. 37). De acordo com Royo (2008), interface é a superfície que separa o homem do aparelho - seja um equipamento eletrônico, um site, um formulário -, e sua função é tornar este produto usável (por meio da avaliação da capacidade e da facilidade de uso), sem deixar de haver um equilíbrio entre forma (estética) e função (usabilidade). Em suma, design de interface é a soma do design de usabilidade com o design visual.

Entretanto, a interface é apenas o meio mediante o qual ocorre a interação entre o ser humano e a máquina. E o que seria uma interação? Segundo Saffer (2010), grosso modo, interação é uma transação entre duas entidades, geralmente uma troca de informações, mas que também pode ser uma troca de bens ou serviços. Sendo assim, o design de interação, como afirmam Preece, Rogers e Sharp (2005), é o design de produtos interativos que forneçam suporte às atividades cotidianas das pessoas, seja em sua casa ou no trabalho.

Já, usabilidade é a capacidade que um sistema interativo, em determinado contexto, oferece ao usuário o cumprimento de tarefas de modo eficaz, eficiente e

\footnotetext{
Os leitores dedicados são dispositivos desenvolvidos exclusivamente para a finalidade de leitura de livros digitais, por isso empregam tecnologias que atuam em favor da leitura textual, com legibilidade similar à leitura em papel. Já os leitores híbridos são computadores de mão, ou tablets, que possuem performances e telas ligeiras mais adequadas à interação.
} 
agradável. É uma composição flexível de aspectos objetivos (relacionados à produtividade) e aspectos subjetivos, relacionados ao prazer na experiência.

Em se tratando de leitores de livros digitais, o estudo a respeito da usabilidade em dispositivos móveis é indispensável, uma vez que estes são considerados computadores de mão, ainda que possuam menos limitações que telefones celulares e smartphones, por exemplo.

É importante destacar que é necessário que o designer dê a devida atenção às necessidades e características do usuário móvel, ao contexto de uso dos computadores de mão, às características das aplicações e às limitações físicas desses equipamentos, uma vez que estes são fatores que influenciam a interação e consequentemente no design da interface (CYBIS; BETIOL; FAUST, 2010).

Para ilustrar essas restrições, tomemos como exemplo a entrada de dados por meio de telas de toque. Uma vez que o toque com os dedos do usuário abrange uma área relativamente grande e sem muita precisão - se comparada à manipulação com o mouse, por exemplo - devem-se utilizar botões suficientemente dimensionados para tal atividade.

As novas tecnologias aplicadas nas mais diversas áreas trouxeram à tona um conjunto muito maior de interesses, de acordo com Preece, Rogers e Sharp (2005). Com isso, como afirmado anteriormente, as metas não são somente focadas na produtividade, mas também na experiência do usuário - os aspectos subjetivos -, as quais procuram estabelecer quais são as preocupações quanto à experiência que ele terá e como se sentirá durante a interação. Sendo assim, os designers estão cada vez mais preocupados com a criação de sistemas que sejam:

- Satisfatórios;

- Agradáveis;

- Divertidos;

- Interessantes;

- Úteis;

- Motivadores;

- Esteticamente apreciáveis;

- Incentivadores da criatividade;

- Compensadores;

- Emocionalmente adequados.

As autoras enfatizam que é preciso reconhecer e entender que é importante que haja um equilíbrio entre as metas de usabilidade e as decorrentes da experiência do usuário. Além disso, nota-se que não é possível a um projeto de design de interação atender a todos esses objetivos. Deve-se "buscar combinações diferentes dessas metas, levando em consideração as necessidades dos usuários. [...] Algumas combinações serão incompatíveis" (PREECE; ROGERS; SHARP, 2005, p. 41).

Definindo-se quais serão as metas de usabilidade e de experiência do usuário que se desejam para a interface a ser projetada, existem princípios do design que servem como forma de orientação ao se projetar o sistema que auxiliam no atingimento destas metas, dentre eles a affordance. 


\subsection{Affordance}

O termo affordance surgiu no final da década de 70 na Psicologia, proposto por Gibson. Durante os anos 80 foi então adaptado por Donald Norman e trazido à luz do Design (BARBOSA; SILVA, 2010). Para Norman, affordance é definida como um conjunto de propriedades reais e percebidas do objeto, principalmente aquelas fundamentais para determinar como o este poderia ser utilizado, afirma Cooper (2007). O autor resume o termo como o entendimento instintivo de como os objetos são manipulados.

Em suma, affordance é o atributo do objeto que permite às pessoas saber como utilizá-lo. Em uma interface gráfica, por exemplo, ícones devem ser projetados para permitir que sejam clicados (ou tocados), barras de rolagem, para que sejam movidas em alguma direção, botões, para que sejam pressionados (PREECE; ROGERS; SHARP, 2005).

De acordo com Gaver (2002), as affordances podem existir independentes de sua percepção por meio de recursos visuais ou cinéticos, por exemplo. Sendo assim, o autor as classifica em três: percebida, escondida e falsa. Dentro do contexto de objetos interativos, pode-se entender a classificação do seguinte modo:

- Affordance percebida: quando o objeto é interativo e é percebido como tal;

- Affordance escondida: quando o objeto é interativo e não é percebido como tal;

- Falsa affordance: quando o objeto não é interativo, porém é percebido como tal;

Barbosa e Silva (2010) alertam para o uso de falsas affordances que podem confundir o usuário no uso da interface. Pode-se dar a impressão de que a interface funciona de certa maneira, quando na verdade funciona de outra forma. Como exemplos tem-se um botão de comando que não leva a lugar algum ou não realiza ação alguma.

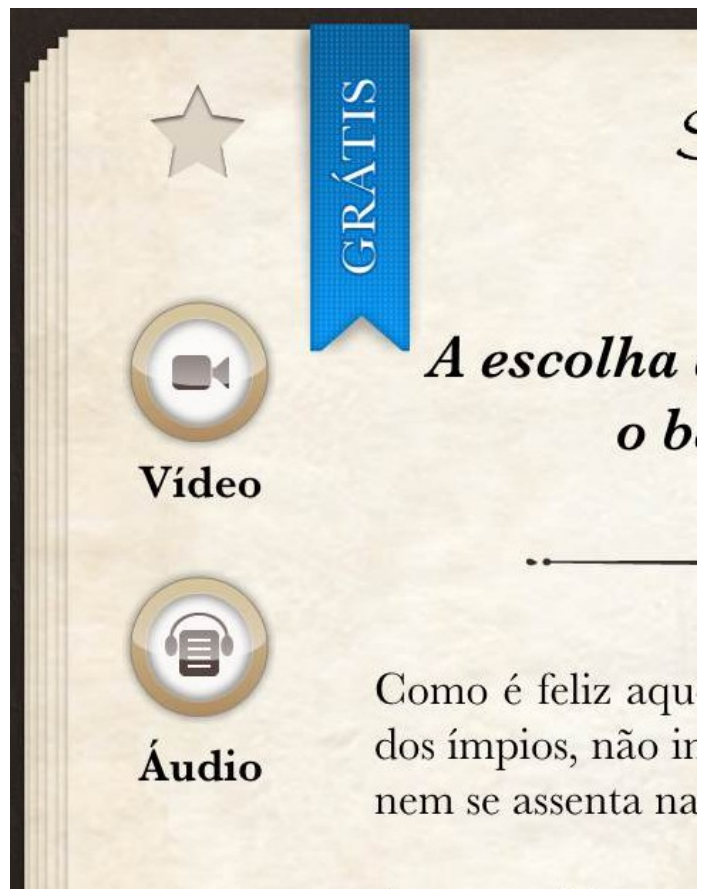


Figura 1 - exemplo de falsa affordance (faixa azul) em um livro digital, em um contexto de affordances percebidas (estrela, vídeo e áudio).

Fonte: Elaborado pelos autores, com base na pesquisa realizada.

Ainda, uma affordance escondida pode fazer com que o usuário não entenda a existência de um objeto interativo, assim como uma falsa affordance pode fazê-lo pensar que um objeto não interativo trará algum tipo de resposta a um comando.

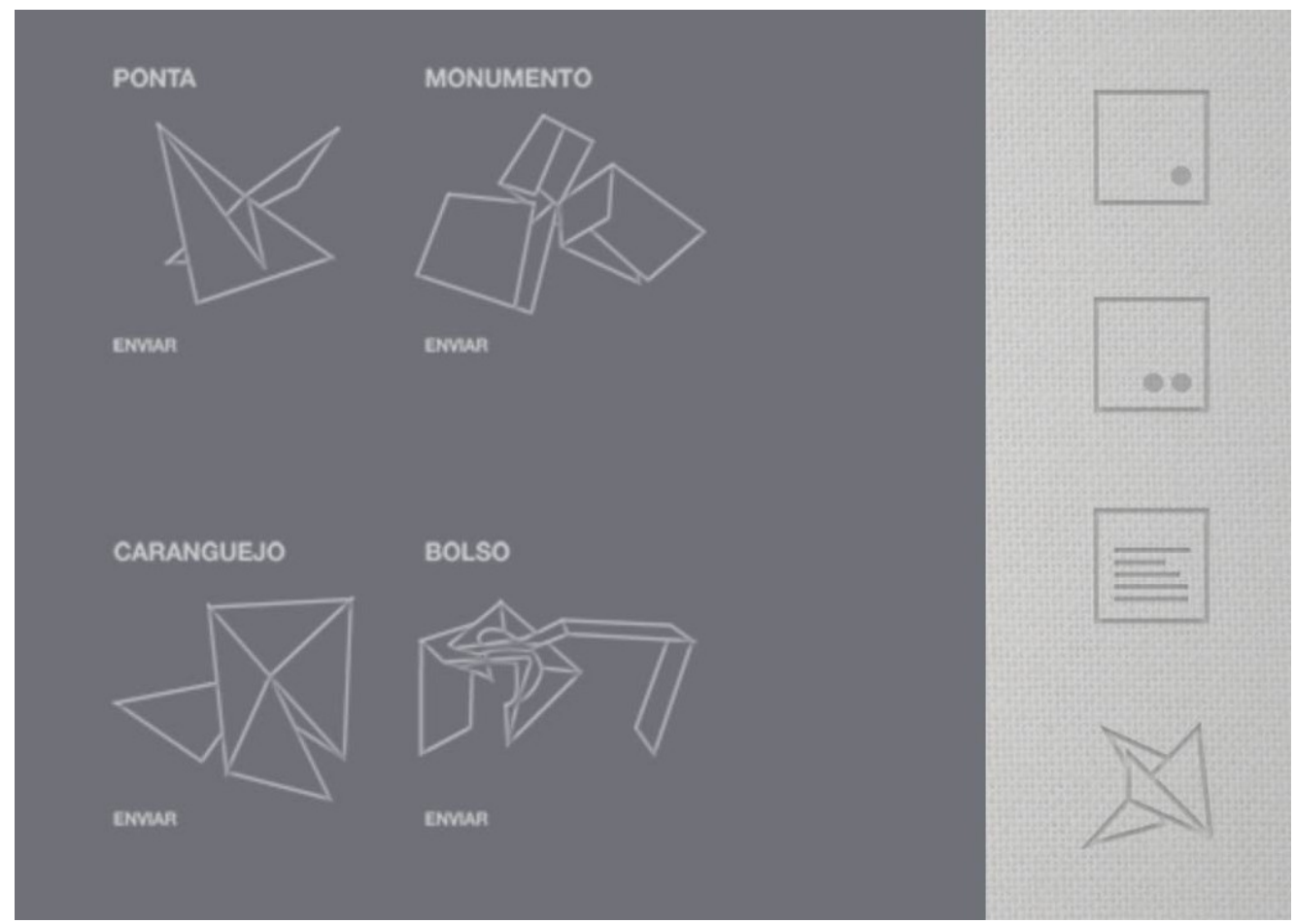

Figura 2 - exemplos de affordances escondidas, à esquerda na imagem.

Fonte: Elaborado pelos autores, com base na pesquisa realizada.

Segundo Cooper (2007), sistemas de estilos e tamanhos de tipos, ícones e outros elementos visuais são definidos de modo a fornecem uma experiência convincente com affordances claras e hierarquia visual, onde estas comunicam comportamento aos usuários.

Em um livro digital, devido ao seu caráter de interface, a importância das affordances se mantém de modo a guiar o usuário sobre o que o sistema é capaz de fazer e como ele pode manipular a interface para fazê-lo, seja para explorar os objetos interativos apresentados, seja para navegar pela estrutura próprio livro.

\subsection{PROCEDIMENTOS METODOLÓGICOS}

\subsection{0 protótipo e o estudo inicial}

O livro digital objeto deste analítico foi desenvolvido para fins didáticos para a plataforma iPad, em sua primeira versão, durante o ano de 2011. Parte do protótipo foi resultado de uma análise investigativa e estatística publicada como "A análise do usuário no projeto de livro digital para tablets" na II Conferência Internacional de Design, Engenharia e Gestão para a inovação, no ano de 2012. Esta buscou inferir o perfil de seus usuários, seus hábitos de leitura, suas preferências e seu grau de 
experiência no uso de tablets, de modo que o produto atendesse da melhor forma possível suas expectativas e necessidades estéticas e ergonômicas (DICK et al., 2012).

Tendo ainda em vista então a ergonomia e a usabilidade, o projeto teve sua navegação somente em um sentido, fluxo simples, indicações de interações e instruções de uso, pois se constatou nas pesquisas que a maioria dos usuários possuía nenhuma ou pouca experiência no uso de tablets. Ainda, como a tecnologia foi um fator de grande importância no projeto, se utilizaram diversas ferramentas interativas, aproveitando-se do potencial da plataforma, pois essas eram novidade aos usuários e tornam a transmissão da informação lúdica e prazerosa.

Por fim, o conteúdo do livro digital trata da formação da imagem e objetivou uma linguagem concisa e objetiva e, por meio do uso das ferramentas interativas, se desejando que seu teor fosse dinâmico e bastante visual (DICK, 2011).

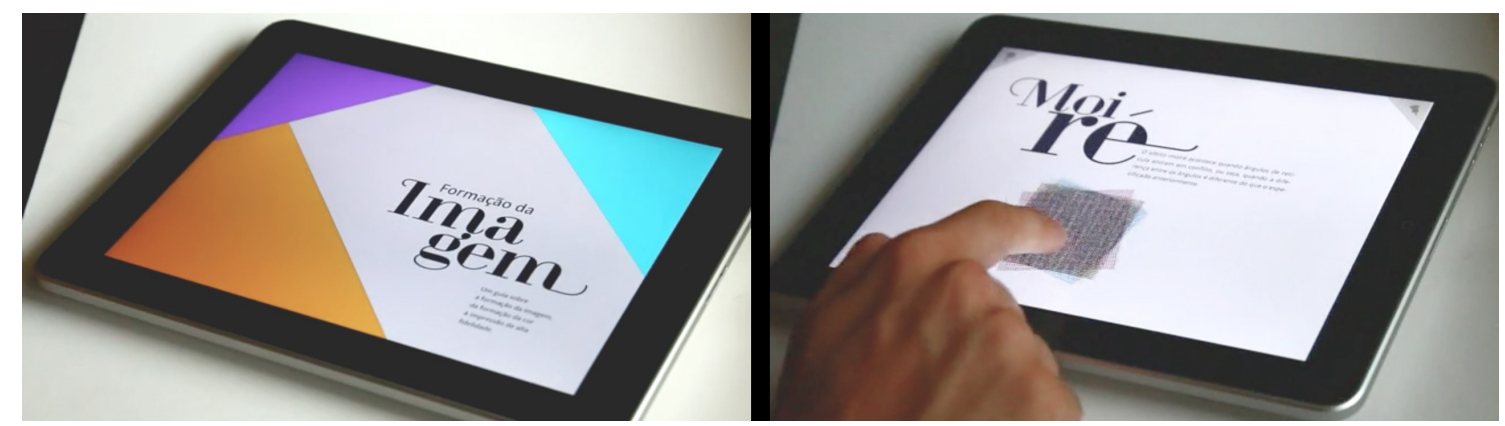

Figura 3 - protótipo em uso.

Fonte: Elaborado pelos autores, com base na pesquisa realizada.

\subsection{Lista de verificação de affordance}

Desenvolvida por Legaspi e Jakhu (2014), a ferramenta IxD Checklist (Interaction Design Checklist) traz uma lista de verificação para que o designer avalie a interface desenvolvida à luz dos seguintes parâmetros: affordance, feedback, simplicidade, estrutura, consistência, tolerância e acessibilidade, os quais levam em consideração aspectos como iconografia, tipografia, interação, navegação e a apresentação da própria interface.

As asserções que se propõem a avaliar a affordance do sistema interativo são as seguintes, em tradução livre:

- Os controles levam ao resultado de modo simples e lógico: avalia-se a coerência dos controles;

- Existe uma metáfora clara entre o mundo real e o controle: objetiva-se avaliar a affordance percebida;

- A função do controle é facilmente determinada em um relance;

- Ícones simbólicos devem ser claros para o usuário: diferente de ícones icônicos, ícones simbólicos devem ser aprendidos e estes devem ser claros ao usuário.

Desse modo, a partir do uso do checklist proposto, analisar-se-ão os itens mencionados acima. Além disso, também serão realizadas considerações gerais, buscando-se avaliar a presença de affordances no protótipo desenvolvido. 


\subsection{RESULTADOS DA ANÁLISE}

Para uma melhor compreensão dos resultados da análise, estes serão apresentados conforme a análise de cada asserção proposta pelo método utilizado.

\subsection{Os controles levam ao resultado de modo simples e lógico}

Esta asserção se relaciona principalmente à navegação e ao direcionamento do usuário. Por exemplo, avalia-se se a presença de uma seta indicadora à direita sugere de fato um acontecimento à direita desta.

Neste sentido, os controles presentes no protótipo são bem claros e simples, realizando ações coerentes com sua indicação visual. Como exemplo, tem-se as setas de navegação (figura 4).

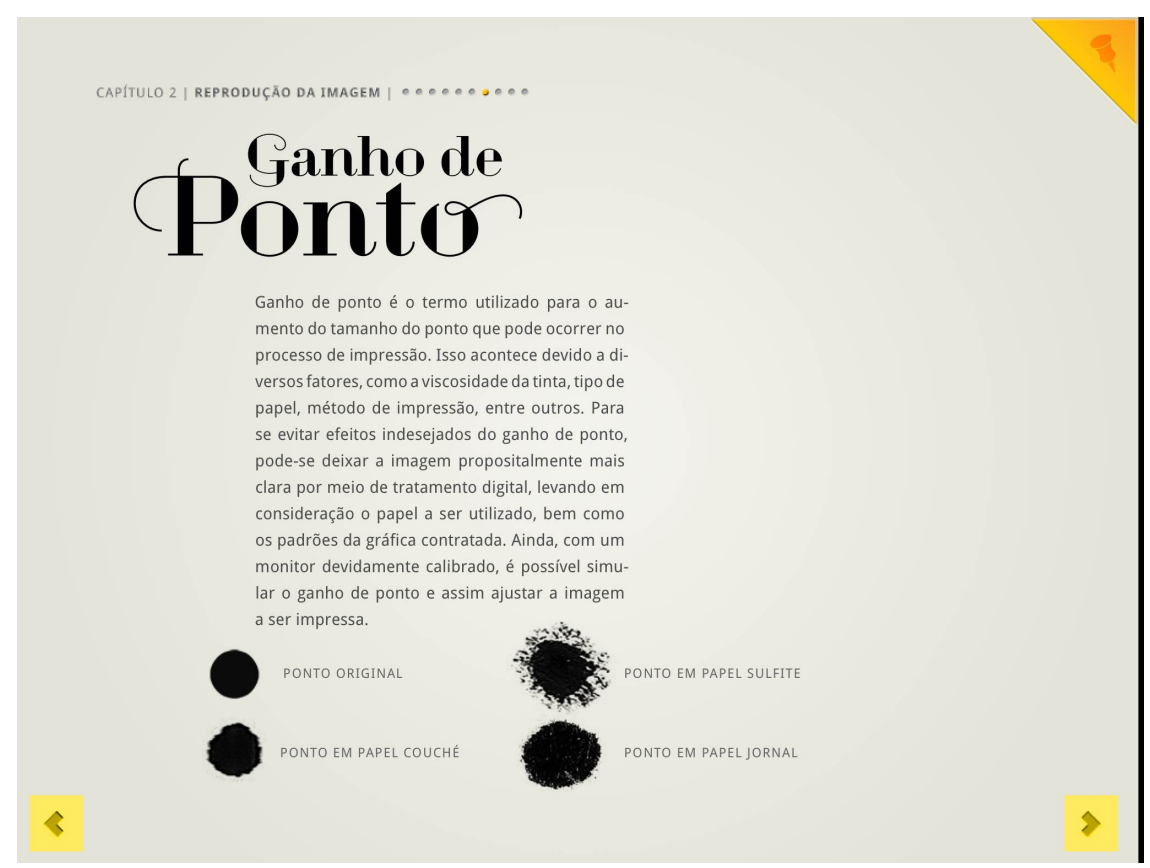

Figura 4 - controles de navegação, na parte inferior da imagem, destacados em amarelo. Fonte: Elaborado pelos autores, com base na pesquisa realizada.

\subsection{Existe uma metáfora clara entre o mundo real e o controle}

Neste aspecto, busca-se avaliar se os controles possuem ações digitais que correspondem às suas ações físicas. Como exemplo, tem-se que botões sugerem que os mesmos devam ser pressionados.

Em relação a esse aspecto, existem algumas falhas e acertos no protótipo analisado. Os principais botões, que se referem ao controle das instruções de interação e às informações de navegação e localização, possuem informações visuais que sugerem que sejam pressionados pelo usuário, seja devido à linguagem visual ou pelo emprego da cor (figura 5). 


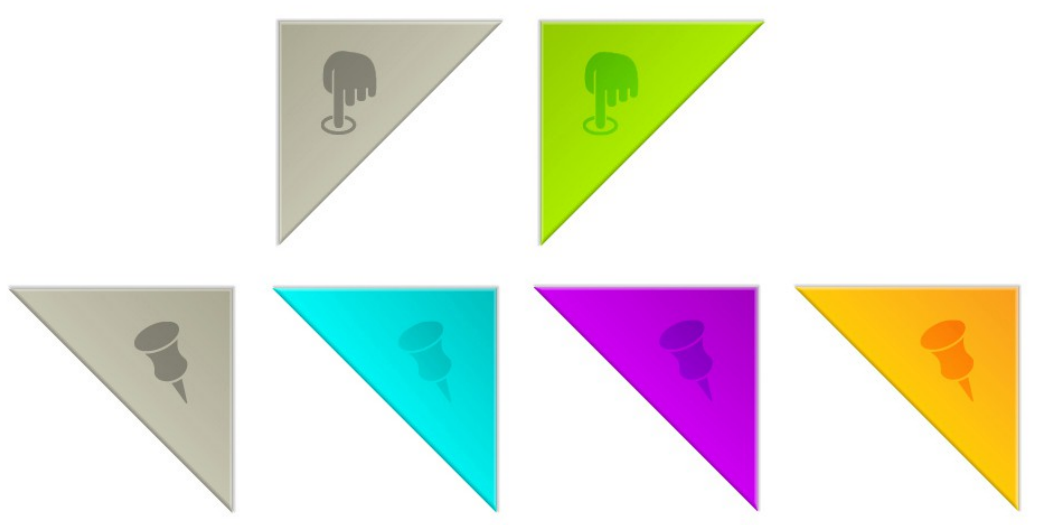

Figura 5 - detalhes dos controles instruções de interação e informações de navegação. Fonte: Elaborado pelos autores, com base na pesquisa realizada.

Já, os botões de navegação, porém, possuem uma linguagem visual inversa ao indicado pelos autores. Ainda que devam ser apertados para executarem uma ação, seu tratamento gráfico sugere que estes já estão pressionados, devido ao baixo relevo, não carregando consigo a indicação visual da sua real reação (figura 6).

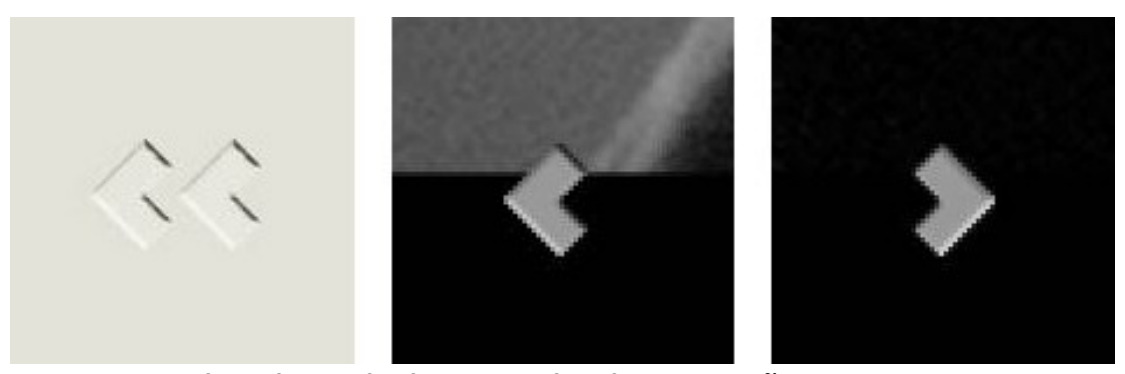

Figura 6 - linguagem visual inadequada dos controles de navegação.

Fonte: Elaborado pelos autores, com base na pesquisa realizada.

\subsection{A função do controle é facilmente determinada em um relance}

Essa asserção busca identificar se a ação a ser realizada pelo controle é de fácil e breve compreensão.

Em relação a este aspecto, considera-se que a ação realizada pelos controles é de rápido entendimento, uma vez que os ícones empregados nestes são também de fácil compreensão e representam graficamente conceitos relacionados à ação, conforme pode ser visto no item seguinte: 5.4 .

\section{4 Ícones simbólicos devem ser claros para o usuário}

Nesta dimensão, é avaliada a compreensão dos ícones empregados na interface. Enquanto os ícones icônicos são relacionados ao seu conceito por semelhança, em ícones simbólicos, seu conceito é uma convenção. Portanto, ao se utilizarem ícones simbólicos, estes devem ser claros ao usuário.

Os ícones utilizados no protótipo são três: setas de direção, uma mão tocando uma superfície e um alfinete (figura 7). À exceção das setas, os outros dois ícones são simbólicos, pois representam, respectivamente, a presença de um objeto interativo e das informações de localização dentro do livro digital. 

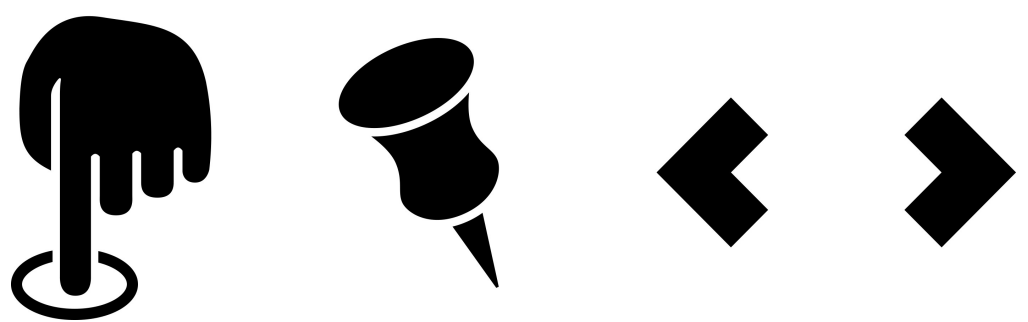

Figura 7 - ícones do protótipo.

Fonte: Elaborado pelos autores, com base na pesquisa realizada.

Estes podem ser considerados claros ao usuário por três principais motivos: (i) a sua ligação direta, ao serem acionados, com os elementos aos quais se referem; (ii) as instruções presentes no início do livro, que esclarecem a função dos botões nos quais os ícones se encontram; e (iii) a utilização de representações concretas e não abstratas em seu desenho.

\subsection{Outras considerações a respeito das affordances do protótipo}

Buscando-se finalizar a análise do protótipo, partiu-se para avaliar de modo geral os níveis de affordance encontrados, com base na classificação trazida por Gaver (2002), apresentada anteriormente.

Ainda que com algumas falhas de representação visual, os principais controles presentes no livro digital podem ser percebidos como objetos passíveis de interação, portanto, suas affordances são percebidas. São eles os controles de indicação de interação, de localização e os direcionadores de navegação.

Já em relação às affordances escondidas, essas estão presentes no protótipo. Existem diversos elementos interativos que não possuem distinção visual em relação a outros elementos não interativos, fazendo com que o usuário não perceba suas affordances. Entretanto, para compensar a ausência de informação visual indicando esses objetos interativos, existem instruções e informações textuais que assim o fazem (figura 8).

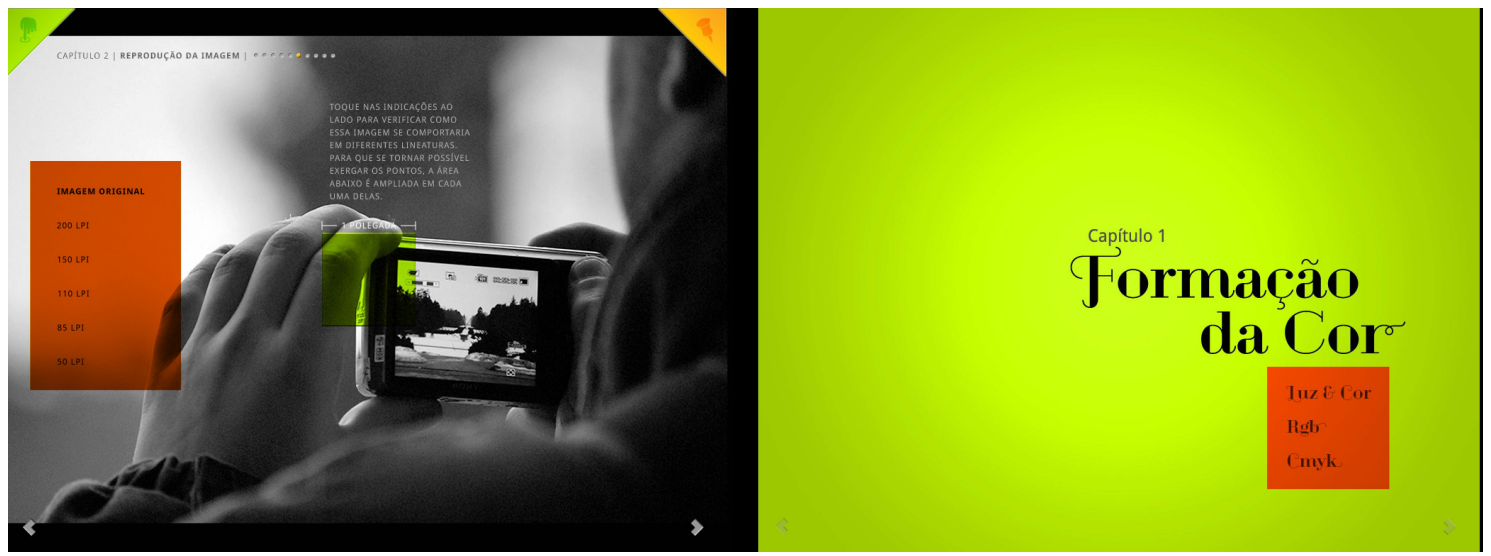

Figura 8 - exemplos de affordances escondidas (áreas destacadas em vermelho).

Fonte: Elaborado pelos autores, com base na pesquisa realizada.

Por fim, em relação às falsas affordances, estas também se fazem presentes, novamente por problemas de representação gráfica. Faz-se o uso de representação tridimensional em elementos que não são interativos. Uma vez que existem elementos com o mesmo tipo de representação que são interativos, o usuário acaba por inferir 
que todos aqueles que assim representados são objetos passíveis de interação (figura 9). Além disso, o usuário também é confundido por existirem affordances escondidas, desse modo, não consegue mais identificar quais são os elementos que de fato são interativos ou não. Em suma, há falta de coerência na representação visual dos elementos que compõe o protótipo, para que aqueles que sejam passíveis de interação tenham suas affordances corretamente compreendidas.

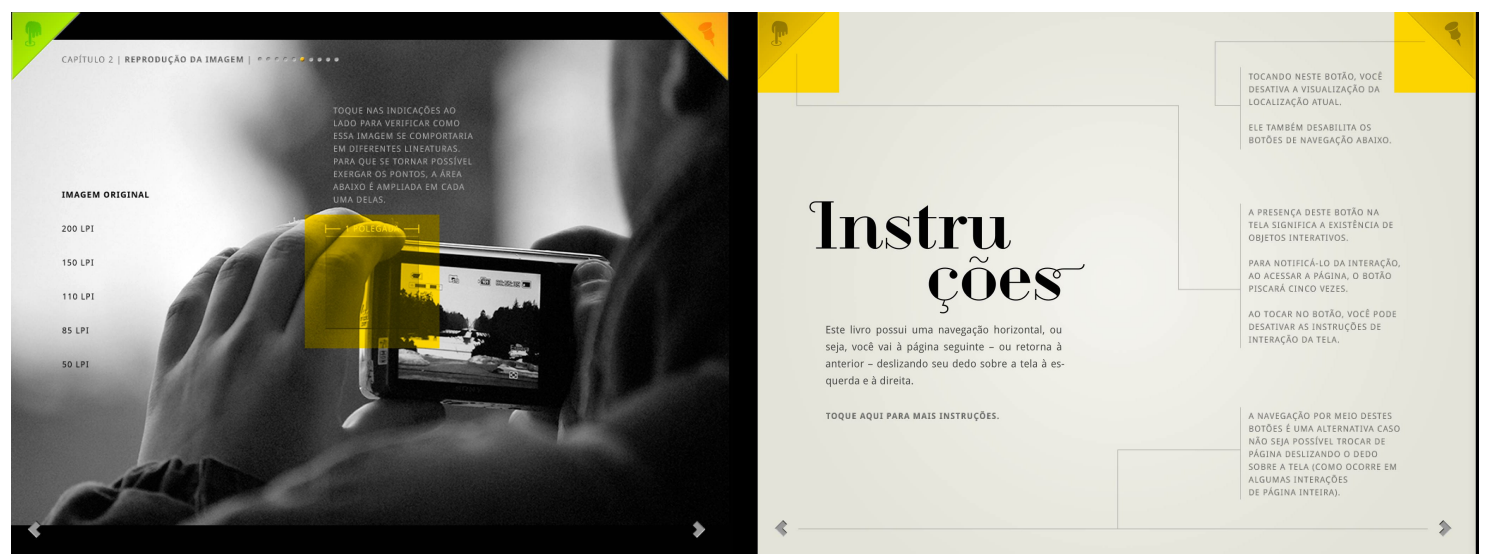

Figura 9 - exemplos de falsas affordances destacadas em amarelo.

Fonte: Elaborado pelos autores, com base na pesquisa realizada.

\subsection{CONCLUSÃO}

O conceito de affordance é fundamental para que se atinjam os requisitos de usabilidade e experiência do usuário em qualquer interface gráfica interativa. Em suma, affordances percebidas são necessárias para a concepção de livros digitais que sejam claros, coesos e de fácil utilização.

Em contrapartida, as falsas affordances, bem como affordances escondidas, contribuem para uma experiência frustrada do usuário, dificultando o atingimento de seus objetivos e por consequência interferindo na sua experiência e na usabilidade do projeto. A partir deste estudo, concluiu-se que ambas podem ser geradas pela falta de coerência visual dos elementos que compõem a interface.

Já, a lista de verificação empregada, ainda que não muito profunda, se mostrou relativamente eficiente na avaliação das affordances, trazendo à luz questionamentos e debates gerais a respeito deste conceito, que levam ao encontro de problemas específicos que possam ser encontrados no objeto avaliado. Ainda, a avaliação das affordances conforme as três classificações propostas por Gaver (2002) complementou a visão geral sobre o tema, pois auxiliou a categorizar os problemas identificados e compreender sua existência.

Por fim, pretende-se ampliar esta pesquisa, trazendo uma visão dos usuários finais perante as affordances, para que esta seja cruzada com a visão apresentada neste estudo. Para tal, será empregado um ensaio de interação baseado em cenário, composto por um questionário pré-ensaio, uma sessão de observação apoiada em um protocolo previamente determinado e, por fim, a aplicação de uma entrevista pósensaio.

\section{REFERÊNCIAS}


BARBOSA, Simone Diniz Junqueira; SILVA, Bruno Santana da. Interação humanocomputador. Rio de Janeiro: Elsevier, 2010.

COOPER, Alan. About Face 3: The Essentials of Interaction Design. Indianapolis: Wiley Publishing, 2007.

CYBIS, W.; BETIOL, A.; FAUST, R. Ergonomia e usabilidade: conhecimentos, métodos e aplicações. 2. ed. São Paulo: Novatec Editora, 2010.

DICK, M. E. A tecnologia como suporte e diretriz ao projeto gráfico de livro digital. 2011. Trabalho de conclusão de curso (Graduação) - Curso de Desenho Industrial, Universidade Federal de Santa Maria, Santa Maria, 2011.

DICK, M. E.; POSSATTI, G. M.; MATTE, V. A.; RAVANELLO, R. B. A análise do usuário no projeto de livro digital para tablets. In: Albertina Pereira Medeiros; Marcelo Gitirana Gomes Ferreira. (Org.). IDEMi - Integração para a inovação. 1ed. Florianópolis: Editora UDESC, 2012, p. 16-31.

GAVER, William W. Technology affordances. Cambridge, 2002. Disponível em: < http://www.cs.umd.edu/class/fall2002/cmsc434-0201/p79-gaver.pdf>. Acesso em: 10 maio 2014.

LEGASPI, Aaron; JAKHU, Amit. IxD (Interaction Design) Checklist. 2014. Disponível em: <http://ixdchecklist.com/>. Acesso em: 10 maio 2014.

LEVY, Pierre. Cibercultura. São Paulo: Ed. 34, 1999.

NASCIMENTO, José Antonio Machado do; AMARAL, Sueli Angélica do. Avaliação de usabilidade na Internet. Brasília: Theasaurus, 2010.

NORMAN, D. Comentário em "User Experience and Experience Design" por HASSENZAHL, Marc. 2011. Disponível em <http://www.interactiondesign.org/encyclopedia/user_experience_and_experience_design.html\#donald+a.

+norman>.

PINSKY, Daniel. O uso do livro eletrônico no ensino superior sob a ótica dos professores universitários e profissionais de editoras. 2009. Dissertação (Mestrado em Administração) - Faculdade de Economia, Administração e Contabilidade, Universidade de São Paulo, São Paulo, 2009. Disponível em: <http://www.teses.usp.br/teses/disponiveis/12/12139/tde-29052009-091004/>.

Acesso em: 10 maio 2014.

PREECE, J.; ROGERS, Y.; SHARP, H. Design de Interação: além da interação homemcomputador. Porto Alegre: Bookman, 2005.

PROCÓPIO, Ednei. O livro na era digital. São Paulo: Giz Editorial, 2010.

ROYO, Javier. Fundamentos do design: Design Digital. 1. ed. São Paulo: Rosari, 2008.

SAFFER, Dan. Designing for Interaction, Second Edition: Creating Innovative Applications and Devices. Berkeley: New Riders, 2010.

SANTAELLA, Lucia. Comunicação Ubíqua. São Paulo: Paulus, 2013.

SILVA, Luiz O. M da. O livro eletrônico: mudando paradigmas. Belém, 2002. Disponível em: <http://www.sibi.ufrj.br/snbu/snbu2002/oralpdf/78.a.pdf>. Acesso em: 01 jun 2011. 